\title{
Growth factor staining patterns in the pig retina following retinal laser photocoagulation
}

\author{
Ming Xiao, David McLeod, John Cranley, Gillian Williams, Mike Boulton
}

\begin{abstract}
Aim-To identify changes in growth factor expression in miniature pig retinas following retinal laser photocoagulation. Methods-Pigs were sacrificed at different times (15 minutes to 42 days) post-laser and the retinas were immunolabelled for basic fibroblast growth factor, insulin-like growth factor I, transforming growth factor $\beta$, epidermal growth factor, transforming growth factor $\alpha$, platelet derived growth factor, vascular endothelial growth factor, and epidermal growth factor receptor. Total mRNA levels were also determined.
\end{abstract}

Results-With the exception of vascular endothelial growth factor, immunoreactivity for all other growth factors studied and epidermal growth factor receptor was observed throughout normal non-lasered control retina, generally being high in the retinal pigment epithelium and low in the neural retina. Changes in growth factor expression following laser photocoagulation were observed only in burn areas and changes were mainly confined to the retinal pigment epithelium and outer nuclear layer. The immunoreactivity within retinal pigment epithelial cells in burn areas was either absent or decreased following laser treatment but returned to normal by 21 days. The immunoreactivity was increased within the outer nuclear layer of burn areas during the healing process but returned to normal by 42 days. Vascular endothelial growth factor immunoreactivity was weak/ absent in the normal retina and remained unchanged following laser photocoagulation. Change of total mRNA levels in burn areas during time post-laser was confined to retinal pigment epithelial cells, being low immediately following photocoagulation and returning to normal by 42 days.

Conclusions-These results demonstrate a temporal alteration in growth factor expression and transcriptional activity in the retina following laser photocoagulation.

(Br f Ophthalmol 1999;83:728-736)

Panretinal photocoagulation for preretinal neovascularisation is an established primary therapy that induces regression of new vessels. ${ }^{1}$ The major sites of retinal damage following laser photocoagulation are in the retinal pigment epithelium (RPE) and outer retina. During the first 2 or 3 weeks after photocoagulation, a scarring process takes place in the local retinal lesion. ${ }^{2-4}$ Histopathologically, at the stage of acute lesions there is retinal tissue damage, RPE hyperplasia, and inflammation..$^{5-7}$ With time, migration and proliferation of RPE cells are observed within the retina, ${ }^{689}$ and at approximately 2 weeks after laser photocoagulation RPE cells are completely regenerated. ${ }^{2}{ }^{1011}$ In addition, retinal glial cell division after laser photocoagulation is thought to be a secondary response to neuronal loss. ${ }^{8}$ By approximately 2 weeks, Müller cells have proliferated and migrated into the damaged areas of the neural retina, where they interdigitate with regenerated RPE cells to form a glial scar. ${ }^{28}$ The modulators that regulate the process of retinal wound healing following laser photocoagulation are poorly understood. Clearly the timing of these processes is dependent on the intensity and type of burn applied. ${ }^{8}$

Peptide growth factors regulate the key processes of wound healing in most tissues of the body - chemotactic migration of inflammatory cells, mitosis of cells within the wound, neovascularisation, and synthesis of extracellular matrix components. ${ }^{12-14}$ The major families of growth factors implicated in wound healing are transforming growth factor $\beta$ (TGF- $\beta$ ), platelet derived growth factor (PDGF), transforming growth factor $\alpha$ (TGF- $\alpha$ ), epidermal growth factor (EGF), insulin-like growth factor I (IGF-I), basic fibroblast growth factor (bFGF), and vascular endothelial growth factor (VEGF). In this study, we investigated changes in profiles of these growth factors and the EGF/TGF- $\alpha$ receptor (EGF-R) in the retina following laser photocoagulation and correlated these findings with changes in intravitreal levels previously reported..$^{15}$ Finally, we assessed total mRNA content to determine if there was a temporal variation in cellular activity in the photocoagulated retina.

\section{Materials and methods}

ANIMALS

Eighteen female Yucatan miniature pigs (Charles River UK Ltd), ages 8-10 months (weight approximately 40-45 kg), were maintained routinely before and after laser treatment under the ARVO statement for the use of animals in ophthalmic and vision research.

LASERS

A prototype diode laser with a spectral emission of $810 \mathrm{~nm}$ (kindly provided by Keeler Ltd, Windsor, Berks) was used for a group of eight animals. However, because of the variability of the laser burns induced by the diode laser a second group of 10 pigs was treated with an emerald laser that, from our clinical experience, we knew was capable of delivering more consistent laser burns. The emerald high 
performance solid state photocoagulator had a frequency doubled neodymium-YAG source with a spectral emission at $532 \mathrm{~nm}$ (Intraoptics (UK) Ltd, Milton Keynes).

RETINAL LASER PHOTOCOAGULATION

The pigs received scatter photocoagulation according to the following protocol. ${ }^{15}$ Each pig was anaesthetised with an intramuscular injection of $20 \mathrm{ml} / \mathrm{kg}$ Saffan (alphaxolone/ $\alpha$-dolone) and maintained on gaseous anaesthesia (3\% halothane with a flow rate of 1.5 litres of oxygen per minute plus 0.75 litres of nitrous oxide per minute). Pupillary dilatation was attained using $1 \%$ tropicamide and $10 \%$ phenylephrine hydrochloride drop instillation. In each experimental group, laser lesions (burns) were applied to the retina of the right eye of each animal using a Keeler Fison indirect ophthalmoscope delivery system and a 20 dioptre condensing lens. Using the diode laser, approximately 1000 burns were produced at $400 \mathrm{~mW}$ power and $200 \mathrm{~ms}$ duration, and with the emerald laser, approximately 2000 burns were produced at $300 \mathrm{~mW}$ power and $100 \mathrm{~ms}$ duration. Spot size was approximately $500 \mu \mathrm{m}$. The left eye was not lasered and served as the control for each animal. After treatment, the anaesthetic agents were withdrawn and the pigs allowed to recover. Animal procedures were performed with the benefit of standard veterinary care and the animals showed no signs of undue stress.

Both eyes of each pig were enucleated under anaesthesia at either 1 hour (diode laser) or 15 minutes (emerald laser) from the start of laser treatment, and at 4,7 , or 21 days for both groups following laser photocoagulation (two animals each for each time point per laser). An additional 42 day time point was included for the emerald laser treated group. Following enucleation each animal was killed.

PREPARATION OF SPECIMENS

Following enucleation, the eyes were immediately dissected by a circumferential incision just behind the ora serrata and the anterior portion of the eye discarded. The vitreous was removed, the eye cups were trisected, and portions of retina/choroid/sclera were: (a) fixed in $2.5 \%$ glutaraldehyde in cacodylate buffer, (b) fixed in $10 \%$ neutral buffered formalin for a minimum of 12 hours and embedded in paraffin wax, or (c) embedded in Tissue-Tek OCT embedding medium and frozen in liquid nitrogen. Pig and human skin were used as positive controls.

Sections $5-7 \mu \mathrm{m}$ thick were cut from both wax and OCT embedded specimens and mounted on aminopropyl triethoxysilane coated microscope slides.

PRIMARY ANTIBODIES

All antibodies were diluted in TRIS buffered saline (TBS) pH 7.6 containing either $1 \%$ normal goat serum or rabbit serum. The antibodies used were as follows:

(a) a rabbit polyclonal antibody (Sigma) that specifically recognises bFGF and shows no cross reactivity with aFGF (1:1500 dilution for wax sections, 1:2000 dilution for cryosections) (b) a mouse monoclonal antibody (provided by Dr A White in School of Biological Sciences, University of Manchester) that recognises IGF-I and has a less than 5\% cross reactivity with IGF-II (1:75 for wax sections, 1:100 for cryosection)

(c) a mouse monoclonal antibody (Oncogene Science) that recognises both TGF- $\beta 2$ and TGF- $\beta 3$, but not TGF- $\beta 1$ (1:10 for wax sections, $1: 50$ for cryosections)

(d) a goat polyclonal antibody (UBI) that recognises PDGF-AA, - $\mathrm{AB}$, and -BB dimers (1:150 for wax sections, 1:200 for cryosections)

(e) a rabbit polyclonal antibody (Oncogene Science) that recognises EGF and shows no cross reactivity with TGF- $\alpha$ (1:50 for cryosections)

(f) a mouse monoclonal antibody raised against residues $34-50$ of TGF- $\alpha$ (Oncogene Science) that shows no cross reactivity with EGF (1:50 for wax sections, 1:100 for cryosections)

(g) a mouse monoclonal antibody raised against residues 985-996 of the EGF-R (Sigma) that specifically recognises the intracellular domain of the EGF-R (1:50 for wax sections, 1:75 for cryosections)

(h) a polyclonal goat anti-human VEGF165 antibody (R\&D systems) raised against purified insect cell line $\mathrm{Sf} 21$ derived recombinant human VEGF165 $(5 \mathrm{~g} / \mathrm{ml})$

(i) a mouse monoclonal antibody against cytokeratin (CK) 19 was used as a specific marker for retinal pigment epithelial cells (1:50 for cryosections).

While these antibodies were raised against human proteins, they also cross react with the corresponding porcine proteins.

\section{IMMUNOCYTOCHEMISTRY}

Wax and/or frozen tissue sections were employed for immunocytochemistry analysis. Cryosections were fixed in acetone for $10 \mathrm{~min}$ utes, air dried at room temperature for 2 hours, and washed in TBS. Wax sections were dewaxed in xylene, rehydrated through a series of graded ethanol, washed in TBS, pretreated with $0.01 \%$ chymotrypsin (Sigma) at $37^{\circ} \mathrm{C}$ for 20 minutes to expose antigens within the tissue, and washed with two 5 minute changes in TBS. Both frozen and wax sections were incubated with undiluted normal goat or rabbit serum, depending on the species of the secondary antibody, in a moist chamber for 10 minutes at room temperature to block nonspecific binding. Excess serum was removed by washing in TBS and the primary antibody was applied for 1 hour at room temperature. After three 5 minute washes in TBS, the sections were incubated for 30 minutes in biotinylated anti-mouse, anti-rabbit, or anti-goat IgG (1:150). After three 10 minute washes in TBS, the sections were incubated with an avidinbiotinylated alkaline phosphatase reaction complex (Dako) for 40 minutes at room temperature. Following extensive washing, the alkaline phosphatase was visualised using a naphthol phosphate/fast red substrate mixture (endogenous alkaline phosphatase activity was 
blocked using levamisole at this stage). Some immunostained sections were counterstained with haematoxylin. Selected nonimmunolabelled sections were stained with haematoxylin and eosin to permit evaluation of the overall morphology of the sections.

Negative controls included (1) omission of the primary antibody, and (2) substitution of the primary antibody with affinity purified mouse, rabbit, or goat IgG at the same concentration as the primary antibody.

TOTAL MRNA STAINING

Dewaxed sections were rehydrated through a series of graded ethanol, washed in DEPC water for 2 minutes, placed in $0.2 \mathrm{~N} \mathrm{HCl}$ for 20 minutes, immersed in $2 \mathrm{X}$ SSC $(0.3 \mathrm{M} \mathrm{NaCl}$ plus $0.03 \mathrm{M}$ sodium tricitrate) for 10 minutes, and exposed to $0.05 \mathrm{M}$ TRIS- $\mathrm{HCl}(\mathrm{pH} 7.6)$ at $37^{\circ} \mathrm{C}$ for 5 minutes. The sections were pretreated with proteinase $\mathrm{K}(5 \mu \mathrm{g} / \mathrm{ml})$ for $30 \mathrm{~min}$ utes at $37^{\circ} \mathrm{C}$. After pretreatment, the tissue sections were placed in $0.2 \%$ glycine in phosphate buffered saline (PBS) for 3 minutes and washed in PBS for 3 minutes. After washing, the control sections were incubated with RNAse $(500 \mu \mathrm{g} / \mathrm{ml})$ at $37^{\circ} \mathrm{C}$ for 30 minutes. Test and control sections were refixed in fresh $0.4 \%$ paraformaldehyde/PBS for 20 minutes and washed in DEPC water for two 5 minute changes. A volume of $100 \mu \mathrm{l}$ of prehybridisation mixture was overlaid onto each section in a moist chamber for 1 hour at $37^{\circ} \mathrm{C}$. The prehybridisation mixture was poured off and the sections were hybridised with $50 \mu$ of digoxigenin labelled oligo dT probe (Pharmacia) in the prehybridisation mixture in a moist chamber overnight at $37^{\circ} \mathrm{C}$. The following day, the slides were placed in $2 \mathrm{X}$ SSC for 1 minute and the coverslips were removed with the sections still in $2 \mathrm{X}$ SSC. The sections were rinsed in $2 \mathrm{X}$ SSC for three 10 minute changes at $37^{\circ} \mathrm{C}$, and then in $2 \mathrm{X}$ SSC for 10 minutes at room temperature. After rinsing in $2 \mathrm{X}$ SSC the sections were immersed in $0.1 \%$ triton $\mathrm{X}-100$ in TBS for 15 minutes at room temperature, washed in TBS for 15 minutes, and immersed in TBS containing $2 \%$ normal sheep serum (NSS) and $0.3 \%$ Triton X-100 for 30 minutes at room temperature. The sections were then incubated with 1:250 alkaline phosphatase conjugated antidigoxigenin antibody (sheep polyclonal) in TBS containing $1 \%$ NSS and $0.3 \%$ Triton X-100 for 2 hours at room temperature. The sections were washed twice for 15 minutes each in TBS and then immersed in veronal acetate buffer for 5 minutes, and coverslips were mounted on slides.

ASSESSMENT OF IMMUNOLABELLING

The degree and pattern of immunolabelling both within and between specimens was assessed by two masked observers using standard light microscopy. The intensity of labelling was graded qualitatively as background, weak, moderate, or intense; background staining was the level of staining seen in the negative controls, "intense" corresponding to the highest level of immunoreactivity observed in the positive controls.

\section{Results}

Morphologically, the retinal damage observed in the lasered areas within 1 hour after diode laser treatment was extremely variable. In mild burns, damage was confined to RPE cells and photoreceptor outer/inner segments. In moderate burns, the outer nuclear layer (ONL) was also damaged. In severe burns, damage extended into the inner nuclear layer (INL) or innermost retinal layers. Some severe burns produced a full thickness destruction of the retina; beneath these burns, Bruch's membrane was completely destroyed, and the choriocapillaris and adjacent choroid were damaged. By 4 days post-laser, damaged photoreceptor cells in burn areas had begun to lose their outer/inner segments or nuclei, leading to the appearance of a subretinal space beneath the ONL of burn areas. Within the space there was some matrix material which was later replaced by a glial scar. Some RPE cells were observed budding off Bruch's membrane while others had located within the space beneath the ONL. At 7 days post-laser, some RPE cells in burn areas had flattened and recovered Bruch's membrane. In addition, multilayers of pigmented cells were present in the subretinal space in most burn areas, and occasional pigmented cells were observed within the ONL. Immunolabelling for cytokeratin 19 was positive in most of these pigmented cells, indicating that they were RPE cells. The photoreceptor cells had been lost in great numbers at this stage. By 21 days post-laser, a glial scar had replaced the photoreceptor cells. The glial scar was most prominent in severe burns which had extended into the inner retinal layers. The RPE cell layer had usually regenerated completely at this stage, consisting of a monolayer of enlarged, non-pigmented or hypopigmented RPE cells on Bruch's membrane.

Emerald laser photocoagulation produced uniform burns of the severe intensity burn type. The histopathological changes were identical to moderate intensity burns created by the diode laser. The morphology of the burns at 42 days post-laser were quite similar to those seen at 21 days post-laser. There was no evidence of overt choroidal neovascularisation in any of the sections examined.

IMMUNOLABELLING CONTROLS

Immunolabelling for all growth factors and EGF-R was found in the epidermal layer of human and pig skin, confirming the activity and cross reactivity of the antibodies between species. The immunolabelling was abolished in sections of pig retinas and skin processed with omission, or substitution, of the primary antibody (see Fig 2 E, F).

With the exception of the anti-EGF antibody, which only produced immunolabelling in frozen sections, all other antibodies reacted with both frozen and wax embedded sections. There was no variability in the immunostaining pattern/intensity between the two types of tissue processing.

NON-LASERED CONTROL EYES

Immunolabelling for all growth factors and EGF-R was observed throughout normal non- 
lasered control retinas of miniature pig eyes, with the intensity of immunoreactivity varying among retinal regions. Moderate to intense immunolabelling was observed for all growth factors (except VEGF) and EGF-R in the $\mathrm{RPE}$, with less or absent immunoreactivity in the outer retina and more in the inner retina. Vascular endothelial growth factor was weak/ absent in the normal retina; weak positive immunostaining was associated with the avascular tissue of the inner retina. The immunolabelling patterns for the growth factors and
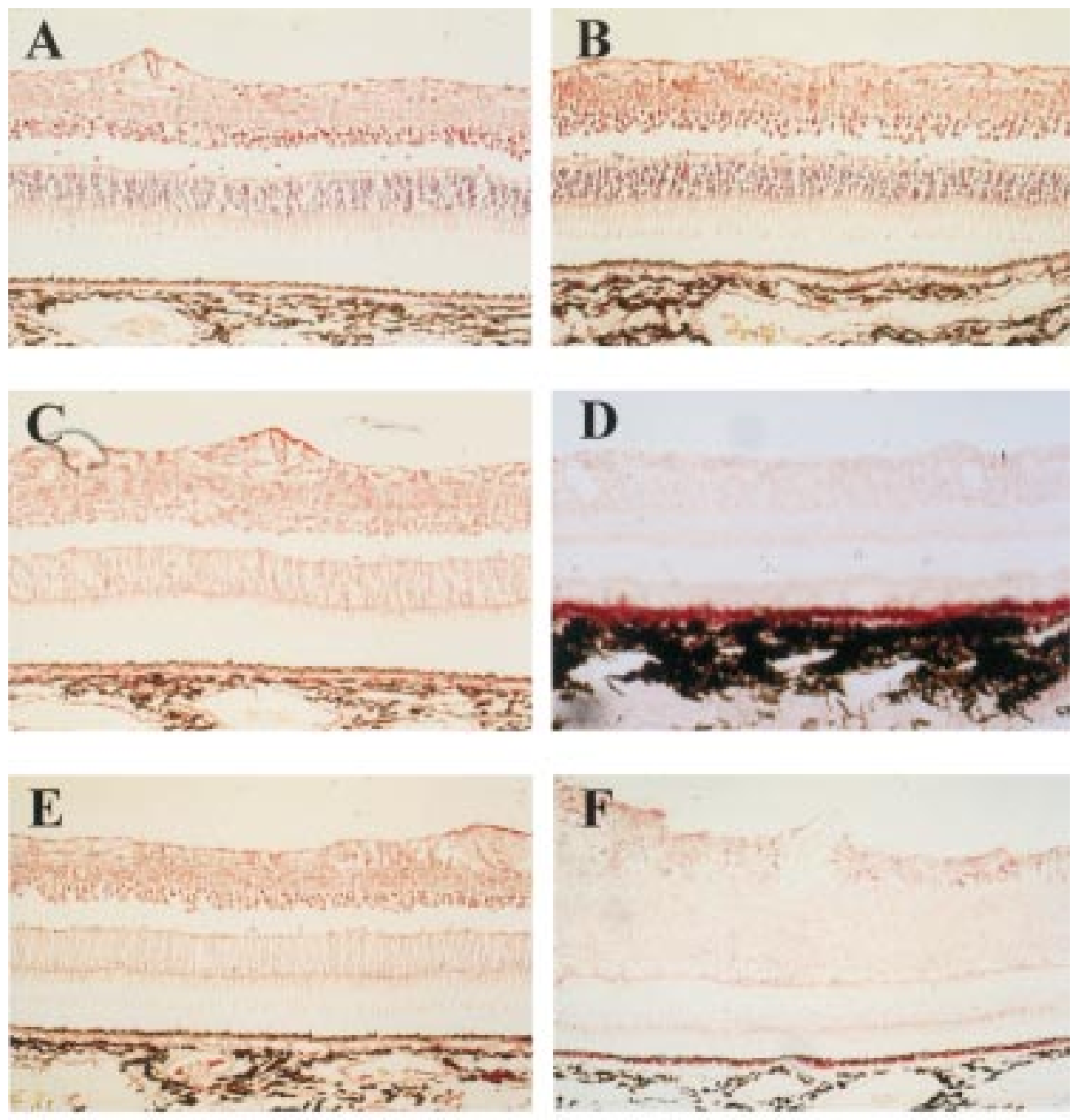

EGF-R in different layers of normal retina (Fig 1) are summarised in Table 1.

LASER TREATED EYES

No obvious differences in staining pattern/ intensity were found with the types of laser used in this study.

\section{Non-lasered regions}

In the non-lasered regions, including areas distal and immediately adjacent to the laser burn, there was no variation in the immunolabelling
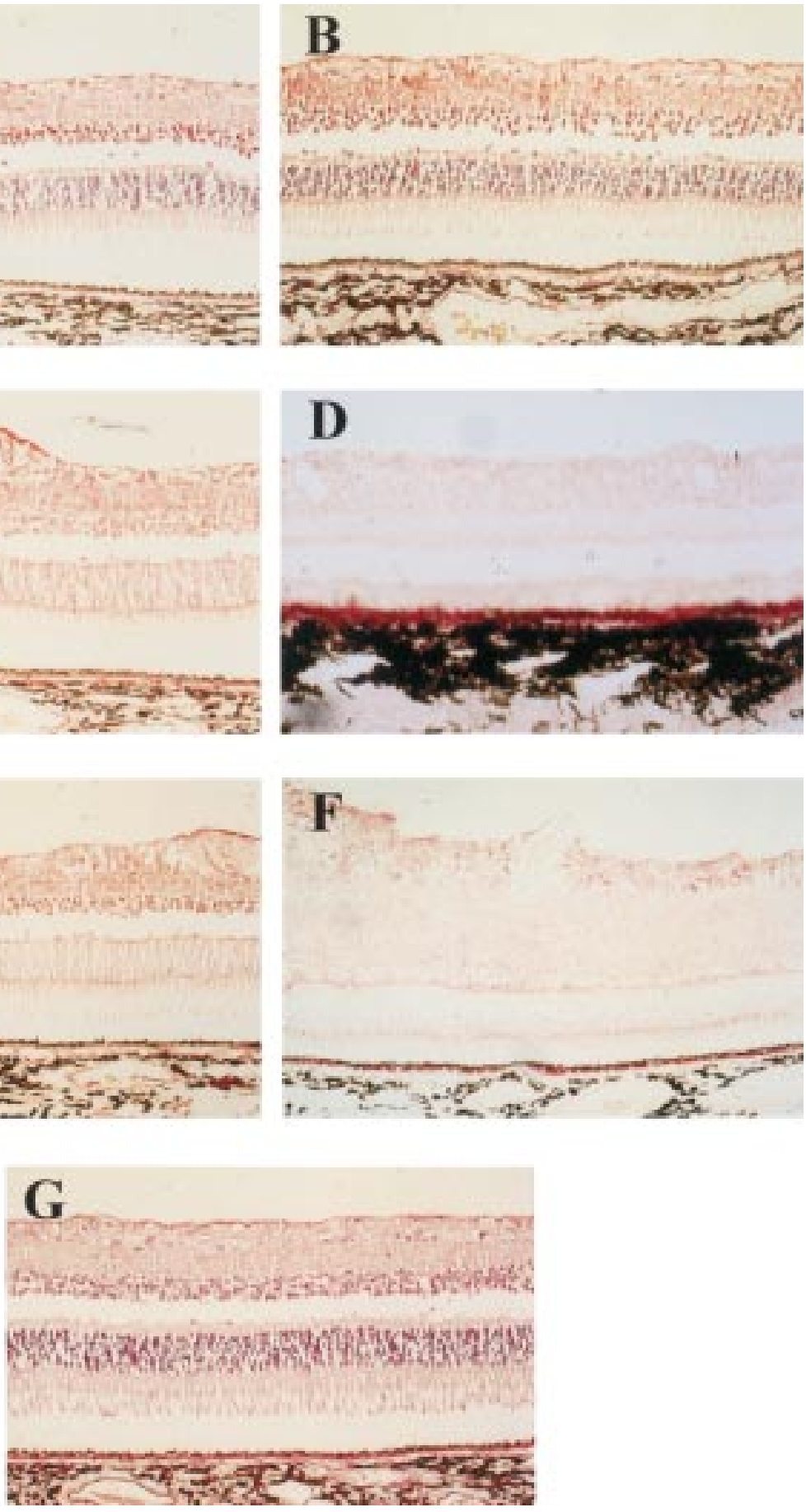

Figure 1 Photomicrographs of normal pig retina showing immunoreactivity for $b F G F(A), I G F-I(B), T G F-\beta(C)$, $E G F(D), T G F-\alpha(E), E G F-R(F)$, and $P D G F-A B(G)$. Immunoreactivity for growth factors and EGF-R can be observed in both the neural retina and RPE; however, the intensity of labelling varies with the retinal region. Original magnification $\times 140$. 
Table 1 Growth factor immunoreactivity in the normal pig retina

\begin{tabular}{lllllllll}
\hline Site & $b F G F$ & $I G F-I$ & $T G F-\beta$ & $P D G F-A B$ & $T G F-a$ & $V E G F$ & $E G F$ & $E G F-R$ \\
\hline RPE & ++ & ++ & ++ & ++ & +++ & $-/+$ & +++ & ++ \\
OS & + & - & - & + & - & - & - & - \\
IS & + & - & + & + & - & - & - & - \\
OLM & + & $+/++$ & + & - & $+/++$ & - & - & $+/++$ \\
ONL & + & + & + & - & - & - & - & - \\
OPL & + & + & + & - & $+/++$ & - & + & - \\
INL & +++ & +++ & ++ & $+/++$ & ++ & $-/+$ & + & ++ \\
IPL & ++ & +++ & ++ & + & ++ & $-/+$ & + & $+/++$ \\
GCL & +++ & +++ & ++ & + & ++ & $-/+$ & + & $+/++$ \\
NFL & ++ & + & ++ & + & ++ & - & + & $+/++$ \\
ILM & ++ & +++ & ++ & $+/++$ & ++ & - & + & $+/++$ \\
\hline
\end{tabular}

$\mathrm{RPE}=$ retinal pigment epithelium; OS=photoreceptor outer segments; IS=photoreceptor inner segments; OLM=outer limiting membrane; $\mathrm{ONL}=$ outer nuclear layer; $\mathrm{OPL}=$ outer plexiform layer; INL=inner nuclear layer; IPL=inner plexiform layer; $\mathrm{GCL}=$ ganglion cell layer; $\mathrm{NFL}=$ nerve fibre layer; ILM=inner limiting membrane.

$-=$ negative $+=$ weak immunoreactivity $++=$ moderate immunoreactivity; $+++=$ intense immunoreactivity; $+/++=$ immunoreactivity between weak and moderate.

patterns for the growth factors or EGF-R at the times following laser treatment compared with control, non-lasered retinas.

Laser treated regions

Spatial and/or temporal changes in the expression of the growth factors (with the exception


Figure 2 Photomicrographs of pig retinas at different times post-laser demonstrating immunoreactivity in the RPE for $(A)$ bFGF which is absent in central RPE of the burn but remains normal in adjacent RPE of the burn at 1 hour post-laser; $(B)$ $T G F-\beta$ which remains normal in RPE of the burn area at 1 hour post-laser; $(C) E G F$ which is absent in RPE of the burn area at 4 days post-laser; (D) EGF-R which is absent in central RPE of the burn but remains normal in adjacent RPE of the burn at 1 hour post-laser. The immunostaining was abolished in sections of pig retinas at 4 and 21 day post-laser processed with substitution of the primary antibody $(E, F)$. Original magnification $B, C, E, F \times 140 ; A \times 270 ; D \times 190$. 
$2 \mathrm{~A}$ ), and in both peripheral and central RPE cells of burn areas at 4 days post-laser. The immunoreactivity for bFGF in the RPE had returned to control levels in some burns by 7 days post-laser and in all burns by 21 days post-laser (Fig 3E). Immunoreactivity for TGF- $\beta$ remained constant in the RPE of burn areas during the time course of the study (Figs 2B, 3B, 3C). Immunoreactivity for EGF was absent in the RPE cells of burn areas at 1 hour and 4 days post-laser (Fig 2C) and had returned to control levels by 7 days post-laser. Immunostaining for TGF- $\alpha$ was absent in the RPE cells of burn areas at 1 hour, 4, and 7 days post-laser and had returned to normal by 21 days post-laser. PDGF-AB immunoreactivity decreased in the RPE cells of burn areas between 4 and 7 days post-laser (Fig 3F) and returned to normal by 21 days post-laser. Immunostaining of the RPE for VEGF was absent in all specimens. Immunoreactivity for EGF-R was decreased or absent in RPE cells at the centre of the burns at 1 hour post-laser (Fig 2D) and completely absent at 4 days postlaser. RPE immunoreactivity for EGF-R was partial at 7 days post-laser and at normal levels by 21 days post-laser. The immunostaining patterns for all the growth factors and EGF-R within the RPE cells of severe intensity burn,
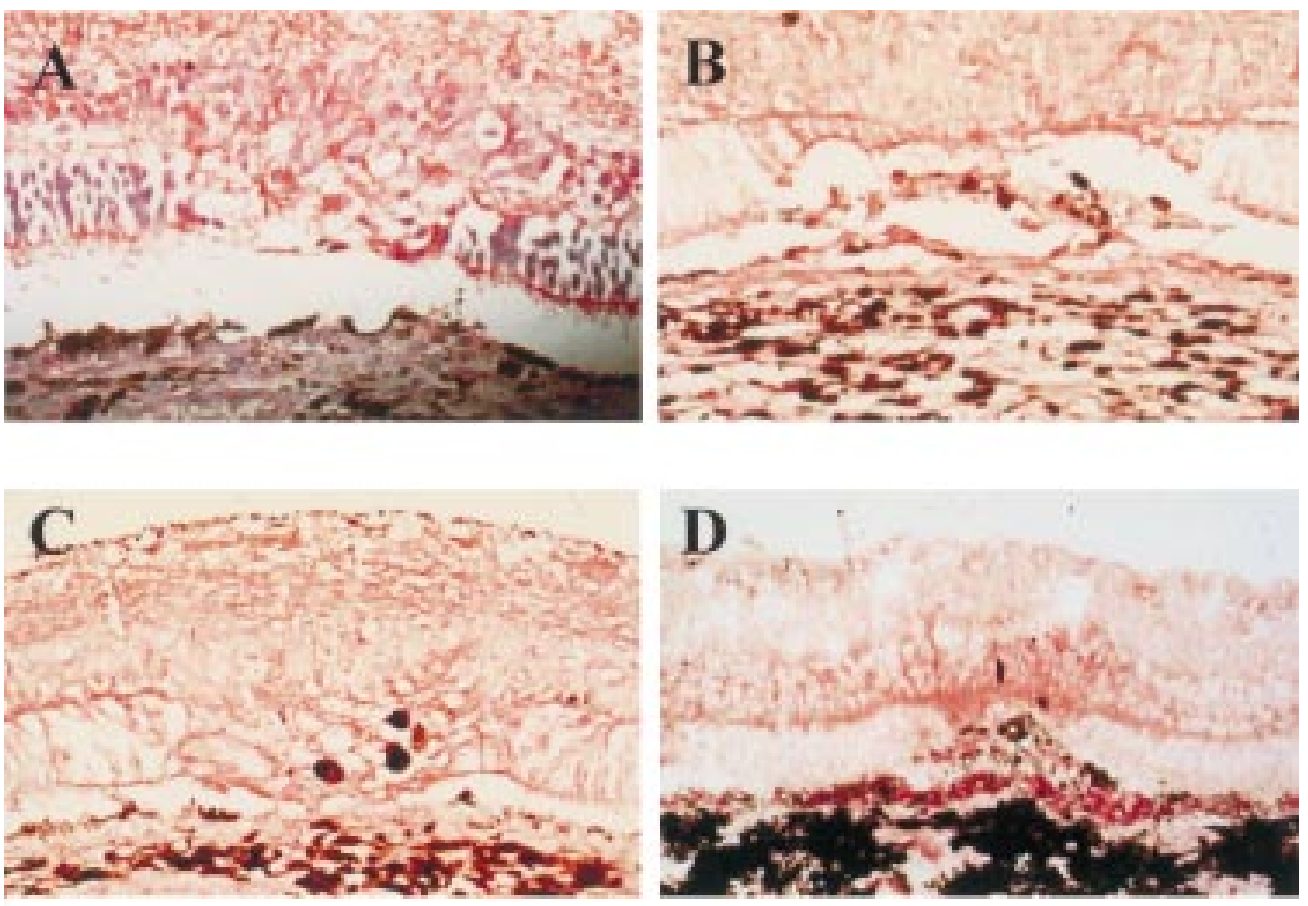

Figure 3 Photomicrographs of pig retinas at different times post-laser demonstrating

immunoreactivity in the ONL and subretinal space of burn areas for $(A)$ IGF-I which is increased in the ONL at 7 days post-laser; (B) TGF- $\beta$ which is intense in the ONL, RPE-like cells and matrix materials in the subretinal space at 4 days post-laser, and $(C)$ in the scar tissue and RPE-like cells at 21 days post-laser; (D) EGF, which is found in the ONL and RPE-like cells in the subretinal space at 7 days post-laser; (E) $b F G F$ which is intense in the scar tissue and RPE-like cells at 21 days post-laser; (F) PDGF-AB which is intense in the subretinal space at 4 days post-laser. Original magnification $\times 270$.

from 4 days onwards were identical to those observed in the moderate intensity burns. At 1 hour post-laser the RPE of moderate and mild intensity burns was similar to those in unlasered regions.

\section{Outer nuclear layer}

Following laser photocoagulation, immunoreactivity for the growth factors (except VEGF) and EGF-R in moderate intensity burns were increased in the ONL of burn areas during the retinal healing process, but the time course of appearance of the increased immunoreactivity varied with individual growth factor. Immunoreactivity in the ONL was significantly increased by 4 days post-laser for IGF-I, TGF- $\beta$, and EGF-R, by 7 days post-laser for bFGF, TGF- $\alpha$, and EGF; and by 21 days post-laser for PDGF-AB (see Fig 3). Immunoreactivity for all growth factors (except VEGF) and EGF-R returned to control levels by 42 -days post-laser. The details of ONL immunoreactivity patterns for the growth factors and EGR-R are summarised in Table 3. The immunostaining profile was identical for severe intensity burns. However, in some particularly severe burns, where scar tissue involved the whole thickness of the retina, intense staining was observed throughout the scar tissue. Unlike the

Table 2 Growth factor immnuoreactivity in the retinal pigment epithelium following laser photocoagulation

\begin{tabular}{|c|c|c|c|c|c|c|c|}
\hline \multirow[b]{2}{*}{$G F s / G F-R$} & \multirow[b]{2}{*}{$C T L$} & \multirow{2}{*}{$\begin{array}{l}\begin{array}{l}\text { Non-lasered } \\
\text { regions }\end{array} \\
1 \text { Hour }-42 \text { days }\end{array}$} & \multicolumn{5}{|c|}{ Laser treated regions } \\
\hline & & & 1 Hour & 4 Days & 7 Days & 21 Days & 42 Days \\
\hline bFGF & ++ & ++ & $+/++$ & $-/+$ & $+/++$ & ++ & ++ \\
\hline IGF-I & ++ & ++ & ++ & - & - & $+/++$ & ++ \\
\hline TGF- $\beta$ & ++ & ++ & $++/+++$ & ++ & ++ & ++ & ++ \\
\hline PDGF-AB & ++ & ++ & ++ & + & + & ++ & ++ \\
\hline TGF- $\alpha$ & +++ & +++ & - & - & - & +++ & +++ \\
\hline EGF & +++ & +++ & - & - & +++ & +++ & +++ \\
\hline EGF-R & ++ & ++ & $+/++$ & - & + & ++ & ++ \\
\hline
\end{tabular}

$\mathrm{GFs}=$ growth factors; GF-R=growth factor receptor; $\mathrm{CTL}=$ control (non-lasered retina). $-=$ negative; +=weak immunoreactivity; ++=moderate immunoreactivity; +++=intense immunoreactivity; /indicates immunoreactivity in different burn areas varied between the limits shown.

Table 3 Growth factor immunoreactivity in the outer nuclear layer following laser photocoagulation

\begin{tabular}{|c|c|c|c|c|c|c|c|}
\hline \multirow[b]{2}{*}{$G F s / G F-R$} & \multirow[b]{2}{*}{$C T L$} & \multirow{2}{*}{$\begin{array}{l}\begin{array}{l}\text { Non-lasered } \\
\text { regions }\end{array} \\
1 \text { Hour-42 days }\end{array}$} & \multicolumn{5}{|c|}{ Laser treated regions } \\
\hline & & & 1 Hour & 4 Days & 7 Days & 21 Days & $\begin{array}{l}42 \\
\text { Days }\end{array}$ \\
\hline bFGF & + & + & + & + & $+/++$ & +++ & + \\
\hline IGF-I & + & + & + & $\begin{array}{l}++/++ \\
+\end{array}$ & +++ & +++ & + \\
\hline TGF- $\beta$ & + & + & + & +++ & +++ & +++ & + \\
\hline PDGF-AB & - & - & - & - & $-1+$ & ++ & - \\
\hline TGF- $\alpha$ & - & - & - & - & $+/++$ & ++ & - \\
\hline EGF & - & - & - & - & ++ & - & - \\
\hline EGF-R & - & - & - & $+/++$ & $+/++$ & ++ & - \\
\hline
\end{tabular}

GFs=growth factors; GF-R=growth factor receptor; $\mathrm{CTL}=$ control non-lasered retina.

$-=$ negative; +=weak immunoreactivity; $++=$ moderate immunoreactivity; $+++=$ intense immunoreactivity; /indicates immunoreactivity in different burn areas varied between the limits shown.

severe and moderate intensity burns, the patterns of immunoreactivity in the mild intensity burns did not change from that observed in the unlasered retina.

\section{Subretinal space}

Intense immunoreactivity for all growth factors (except TGF- $\alpha$ and VEGF) was found in pigmented cells in the subretinal space at 4 or 7 days post-laser (Fig 3B, D, F), and intense immunostaining for IGF-I, bFGF, and TGF- $\beta$ persisted within the pigmented cells in the scar tissue until 21 days post-laser (Fig 3C, E).

Moderate immunolabelling for $\mathrm{bFGF}$ and intense immunolabelling for TGF- $\beta$ were observed within the matrix materials in the subretinal space at both 4 and 7 days postlaser; this staining was adjacent to the pigmented cells within the space. Intense immunoreactivity for bFGF and TGF- $\beta$ were present within the scar tissue that filled the subretinal space at 21 days post-laser (Fig 3C,

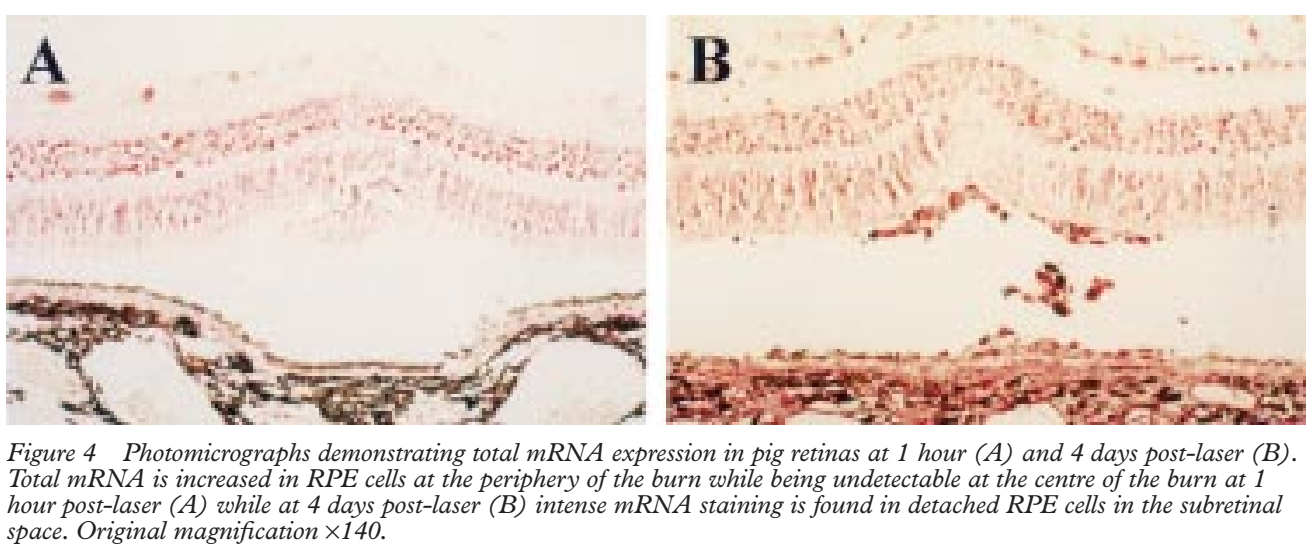

Figure 4 Photomicrographs demonstrating total $m R N A$ expression in pig retinas at 1 hour $(A)$ and 4 days post-laser (B). Total $m R N A$ is increased in RPE cells at the periphery of the burn while being undetectable at the centre of the burn at 1 hour post-laser $(A)$ while at 4 days post-laser $(B)$ intense $m R N A$ staining is found in detached RPE cells in the subretinal space. Original magnification $\times 140$.
E), but this was reduced by 42 days post-laser. Intense immunostaining for PDGF-AB was observed within the subretinal space at 4 and 7 days post-laser (Fig 3F); this staining was not associated with the pigmented cells within the space and had disappeared by 21 days post-laser.

TOTAL MRNA EXPRESSION

The variation in the expression pattern of total mRNA in the laser treated regions was mainly confined to RPE cells, both those attached to Bruch's membrane and those within the subretinal space and retina. By 1 hour post-laser, the level of total mRNA was increased within the RPE cells in the mild mRNA levels were highest in the periphery of the burn and lowest, or non-detectable, in the centre (Fig 4A). By 4 days post-laser, high levels of mRNA were observed in detached RPE cells in the subretinal space and retina (Fig 4C). By 7 days, total mRNA levels within attached RPE cells returned to normal but remained high in detached RPE cells until 21 days post-laser. Despite the obvious gliosis associated with the wound healing process, increased mRNA levels were not evident in the inner retina. No staining was observed in control sections which had been pretreated with RNAse.

\section{Discussion}

The morphological changes observed during the time course of this study agree with those previously reported for human, monkey, and rabbit. ${ }^{4} 1617$ Furthermore, we have demonstrated that the growth factors and EGF-R are present throughout normal pig retina, and their pattern and intensity of expression varies with cellular activity in the retina following photocoagulation. The immunolabelling patterns in the normal pig retina are similar to those previously reported for a variety of species; bFGF, ${ }^{18-20}$ IGF-I, ${ }^{21}$ TGF- $\beta \mathrm{s},{ }^{22}{ }^{23}$ $\mathrm{PDGF}^{24}$ and TGF- $\alpha$, EGF and their receptor. ${ }^{25}$ Although TGF- $\beta 2$ has been analysed in the vitreous and retina following scatter laser photocoagulation ${ }^{26}{ }^{27}$ this is the first study to characterise the change in immunostaining profile of a spectrum of growth factors known to be involved in wound repair.

The absent/decreased immunoreactivity for the growth factors and EGF-R within RPE intensity burns; in more intense burns, RPE 
cells in burn areas may be due to cellular damage and/or decreased production. The RPE is the primary site of the photocoagulation and cellular damage may cause release or destruction of growth factors. If released, growth factors may diffuse outwards into the choriocapillaris, into the vitreous, be rapidly degraded, and/or bind to respective receptors (or extracellular matrix components) elsewhere in the retina, and be rapidly internalised and degraded. A transient reduction in production of these growth factors and EGF-R by RPE cells may also occur in the burn areas. The observation of lower or undetectable levels of total mRNA within the RPE in burn areas immediately after laser is indicative of a downregulation of cellular status but studies using specific gene probes are essential to confirm the effect of laser photocoagulation on transcription of specific growth factor and growth factor receptor genes.

The finding of increased ONL immunoreactivity for the growth factors (except VEGF) and EGF-R in laser wound areas may reflect production of growth factors and EGF-R by retinal glial cells (Müller cells) which extended into the wound areas during the retinal healing process. Neuronal loss in the retina is believed to be accompanied by a repair process in which the retinal glial cells play a critical role. The involvement of Müller cells in wound healing after laser photocoagulation has been demonstrated. $^{2}{ }^{28}$ Immunolabelling for the growth factors and EGF-R was present throughout the inner retinal layers, particularly in the inner nuclear layer and inner limiting membrane, suggesting an autocrine and/or paracrine role for the growth factors in modulating retinal Müller cell behaviour. Exogenous EGF increased DNA synthesis in rat retinal Müller cells in vitro ${ }^{29}$ and stimulated proliferation of cultured rabbit retinal Müller cells. ${ }^{30}$ PDGF had both mitogenic and chemotactic effects on human and rat retinal Müller cells in vitro, ${ }^{31} 32$ and bFGF was a potent mitogen for cultured bovine retinal Müller cells. ${ }^{33}$ These findings suggest that PDGF, bFGF, and EGF may influence Müller cell activity in retinal healing. The role of Müller cells in the synthesis of these growth factors will depend on the use of in situ hybridisation techniques, which were not employed in the present study owing the lack of probes appropriate for pig tissue. It has been hypothesised that the upregulation of FGF in the retina, as observed in this study, may prolong cell survival. ${ }^{34}$ However, this effect may be species dependent since the staining pattern and temporal expression differ between mouse, rat, and pig tissue.

Materials with moderate/intense immunoreactivity for bFGF and TGF- $\beta$ within the subretinal space at 4 and 7 days post-laser may represent cellular debris or be synthesised by adjacent pigmented cells. Intense immunoreactivity for $b F G F$ and $T G F-\beta$ within the pigmented cells suggests an autocrine role for these growth factors in modulating the behaviour of these pigmented cells. The pigmented cells in the subretinal space had positive immunoreactivity for cytokeratin 19 , confirm- ing that these are RPE cells. The subretinal space was eventually replaced by the glial scar during the retinal healing process.

Minimal VEGF immunoreactivity in the normal retina is in keeping with other studies. ${ }^{35} 36$ There was no increase in VEGF immunoreactivity after photocoagulation in either the retina or choroid following scatter laser photocoagulation of the retina. This is in agreement with others who only demonstrated immunostaining localised to choroidal neovascularisation following photocoagulation in the rat or primate retina. ${ }^{37}{ }^{38}$ No choroidal neovascularisation was observed in this study. However, Shen et al have recently reported a peak in VEGF activity at 3-5 days in the RPE and choroid after krypton laser treatment. ${ }^{39}$ This difference may well reflect the greater severity of burns compared with those in this study.

The results for IGF-I immunolabelling of the inner retina were surprising but in keeping with previously reported intravitreal levels post-laser photocoagulation. ${ }^{15}$ This increase in IGF-I post-laser is contrary to the proposed roles of this growth factor in preretinal neovascularisation. However, overall intraretinal levels of IGF-I may be little changed since IGF-I immunoreactivity could not be detected in the $\mathrm{RPE}$ at 4 and 7 days post-laser. Furthermore, the previously reported increase in IGF binding proteins post-laser ${ }^{15}$ may negate the effect of IGF-I to stimulate retinal endothelial cell behaviour.

This study did not address the role of inflammatory cells. Inflammatory cells, which play an important role in wound healing responses and release a variety of growth factors, have been identified in laser burns. ${ }^{80-42}$ Unfortunately, it was not possible to identify the inflammatory cells in the lasered pig retinas in the present study because antibody markers were unavailable for pig tissue.

In addition to local production, the increase in some growth factors in laser burns may come from the influx of serum proteins entering the healing retina following breakdown of the blood-retinal barrier. Intense immunolabelling for PDGF-AB within the subretinal space at both 4 and 7 days post-laser was not associated with pigmented cells suggesting that the PDGF may be serum derived.

The immunohistochemical changes in intraretinal growth factors show a reasonable correlation with intravitreal levels of IGF-I and bFGF previously reported for the same experimental animals. ${ }^{15}$ However, immunostaining for TGF- $\beta$ did not parallel intravitreal levels; TGF- $\beta$ immunolabelling was increased at 4-21 days post-laser in the burn areas while intravitreal levels were dramatically decreased up to 7 days post-laser before returning to normal. This is in contrast with the study by Ishida et $a l,{ }^{27}$ in which an increase in TGF- $\beta 2$ protein and $\mathrm{mRNA}$ in the retina was mirrored by a rise in intravitreal TGF- $\beta 2$ levels. This difference may be due to species variation (relative vitreous volume is tiny in rat compared with pig eyes), the intensity of the burn, and/or the number of burns. 
Growth factors regulate many of the processes crucial for normal wound healing. ${ }^{12} 1343$ TGF- $\beta$ is a chemoattractant for inflammatory cells and promotes matrix deposition. PDGF, EGF, TGF- $\alpha$, and FGF promote RPE and glial cell proliferation. IGF-I is a potent cell survival factor as well as being strongly implicated in the pathobiology of preretinal neovascularisation. It seems likely that these growth factors work in harmony to elicit wound repair which culminates in the formation of a glial scar. The present study shows a temporal variation in growth factor expression in the retina following laser photocoagulation which infers that retinal wound healing after laser photocoagulation is regulated by growth factors in an autocrine/ paracrine manner. From the immunohistochemical data it is likely that retinal pigment epithelial cells and Müller glia play a contributory role in retinal wound healing (via growth factors synthesis) in the pig retina. It should be emphasised that laser photocoagulation was undertaken in normal retinas and that, while changes in growth factor profiles correlate with a wound healing response, they may not reflect the changes associated with laser photocoagulation of retinas exhibiting neovascularisation in which growth factors are already upregulated. Further studies are required to identify whether a change in growth factor levels is important in the regression of preretinal neovascularisation.

This work was supported by the Guide Dogs for the Blind Association and Manchester Royal Eye Hospital. We are indebted to Keeler Ltd, Windsor, Berks, for loaning us the prototype diode laser.

1 Diabetic Retinopathy Study Research Group. Photocoagulation treatment of proliferative diabetic retinopathy: the second report of diabetic retinopathy study findings. Ophthalmology 1978;85:82-105.

2 van der Zypen E, Fankhauser F, Raess K, et al. Morphologic findings in the rabbit retina following irradiation with the free-running neodymium-YAG laser. Disruption of Bruch's membrane and its effect on the scarring process in the retina and choroid. Arch Ophthalmol 1986;104:1070-7.

3 Vogel M, Schafer F, Stuke M, et al. Animal experiments for determination of an optimal wavelength for retinal coagulations. Graefes Arch Clin Exp Ophthalmol 1989;227: 227-80.

4 Wallow I, Sponsel W, Stevens T. Clinicopathologic correlation of diode laser burns in monkeys. Arch Ophthalmol 1991;109:648-53.

5 Smiddy W, Fine S, Quigley H, et al. Comparison of krypton and argon laser photocoagulation. Results of stimulated clinical treatment of primate retina. Arch Ophthalmol 1984; 102:1086-92.

6 Smiddy W, Fine S, Quigley H, et al. Cell proliferation after laser photocoagulation in primate retina. An autoradiographic study. Arch Ophthalmol 1986;104:1065-9.

7 Marshall J, Bird A. A comparative histopathological study of argon and krypton laser irradiations of the human retina. BrF Ophthalmol 1979;63:657-68.

8 Marshall J, Clover G, Rothery S. Some new findings on retinal irradiation by krypton and argon lasers. In: Birngruber series 1984;36:21-37. The Hague: Dr W Junk.

9 McMullen W, Garcia C. Comparison of retinal photocoagulation using pulsed frequency-doubled neodymium-YAG lation using pulsed frequency-doubled neod

10 Pollack A, Korte G. Restoration of the outer blood-retinal barrier after krypton laser photocoagulation. Ophthalmic Res 1993;25:201-9.

11 Roider J, Michaud N, Flotte T, et al. Response of the retinal pigment epithelium to selective photocoagulation. Arch Ophthalmol 1992;11:1786-92.

12 Bennett N, Schultz G. Growth factors and wound healing: biochemical properties of growth factors and thei receptors. Am $\mathcal{F}$ Surg 1993;165:728-37.

13 Bennett NT, Schultz GS. Growth factors and wound healing: Part II. Role in normal and chronic wound healing. Am F Surg 1993;166:74-81.
14 Clark RA. The molecular and cellular biology of wound repair. New York and London: Plenum Press, 1996.

15 Xiao M, Khaliq A, Moriarty P, et al. The effect of scatter laser photocoagulation on intravitreal levels of growth factors in the miniature pig. Curr Eye Res 1996;15:923-31.

16 McHugh J, Marshall J, Capon M, et al. Transpupillary retinal photocoagulation in the eyes of rabbit and human using a diode laser. Lasers Light Ophthalmol 1988;2:125-43.

17 Brancato R, Pratesi R, Leoni G, et al. Histopathology of diode and argon laser lesions in rabbit retina. Invest Ophthalmol Vis Sci 1989;30:1504-10.

18 Hanneken A, de Juan E, Lutty G, et al. Altered distribution of basic fibroblast growth factor in diabetic retinopathy. Arch Ophthalmol 1991;109:1005-11

19 Morimoto A, Matsuda S, Uryu K, et al. Light- and electronmicroscopic localization of basic fibroblast growth factor in adult rat retina. Okajimas Folia Anat Fpn 1993;70:7-12.

20 Ohsato M, Hayashi $\mathrm{H}$, Oshima K, et al. In situ localization of basic fibroblast growth factor protein and mRNA in the retina. Ophthalmic Res 1997;29:24-30.

21 Charkrabarti S, Ghahary A, Murphy LJ, et al. Insulin-like growth factor-I expression is not increased in the retina of diabetic BB/W-rats. Diabetes Res Clin Pract 1991;14:91-7.

22 Lutty G, Merges C, Threlkeld A, et al. Heterogeneity in localization of isoforms of TGF- $\beta$ in human retina, vitreous, and choroid. Invest Ophthalmol Vis Sci 1993;34: $477-87$.

23 Pfeffer B, Flanders K, Gurin C, et al. Transforming growth factor beta 2 is the predominant isoform in the neural retina, retinal pigment epithelium-choroid and vitreous of the monkey eye. Exp Eye Res 1994;59:323-33.

24 Robbins S, Mixon R, Wilson D, et al. Platelet-derived growth factor ligands and receptors immunolocalized in proliferative retinal diseases. Invest Ophthalmol Vis Sci 1994;35:3649-63.

25 Patel B, Hiscott P, Charteris D, et al. Retinal and preretinal localisation of epidermal growth factor, transforming growth factor alpha, and their receptor in proliferative diabetic retinopathy. Br f Ophthalmol 1994;78:714-18.

26 Ie D, Gordon L, Glaser B, et al. Transforming growth factor-beta 2 levels increase following retinal photocoagulaion. Curr Eye Res 1994;13:743-6.

27 Ishida K, Yoshimura N, Yoshida M, et al. Upregulation of transforming growth factor- $\beta$ after pan retinal photocoagulation. Invest Ophthalmol Vis Sci 1998;39:801-7.

28 Tassignon M, Stempels N, Nguyen-Legros J, et al. The effect of wavelength on glial fibrillary acidic protein immunoreactivity in laser-induced lesions in rabbit retina. Graefes Arch Clin Exp Ophthalmol 1991;229:380-8.

29 Roque R, Caldwell R, Behzadian M. Cultured Müller cells have high levels of epidermal growth factor receptors. Invest Ophthalmol Vis Sci 1992;33:2587-95.

30 Scherer J, Schnitzer J. Growth factor effects on the proliferation of different retinal glial cells in vitro. Brain Res Dev Brain Res 1994;80:209-21.

31 de Juan E, Dickson JS, Hjelmeland L. Serum is chemotactic for retinal-derived glial cells. Arch Ophthalmol 1988;106: 986-90.

32 Uchihori Y, Puro D. Mitogenic and chemotactic effects of platelet-derived growth factor on human retinal glial cells. Invest Ophthalmol Vis Sci 1991;32:2689-95.

33 Mascarelli F, Tassin J, Courtois Y. Effect of FGFs on adult bovine Müller cells: proliferation, binding and internalization. Growth Factors 1991;4:81-95.

34 Xiao M, Sastry S, Li Z, et al. Effects of retinal laser photocoagulation on photoreceptor bFGF and survival. Invest Ophthalmol Vis Sci 1998;39:618-630.

35 Lutty G, McLeod D, Merges C, et al. Localization of vascular endothelial growth factor in human retina and choroid. Arch Ophthalmol 1996;114:971-977.

36 Boulton M, Foreman D, Williams G, et al. VEGF localisation in diabetic retinopathy. $\mathrm{Br} \quad \mathcal{F}$ Ophthalmol 1998;82:561-568.

37 Ishibashi T, Hata Y, Yoshikawa H, et al. Expression of vascular endothelial growth factor in experimental choroidal neovascularisation. Graefes Arch Clin Exp Ophthalmol 1997;235:159-67.

38 Yi X, Ogata N, Komada M, et al. Vascular endothelial growth factor expression in choroidal neovascularisation in rats. Graefes Arch Clin Exp Ophthalmol 1997;235:313-19.

39 Shen W, Yu M, Barry C, et al. Expression of cell adhesion molecules and vascular endothelial cell growth factor in experimental choroidal neovascularisation in the rat. $\mathrm{Br} f$ Ophthalmol 1998;82:1063-71.

40 Ishikawa Y, Momoeda S, Yoshitomi F. Origin of macrophages in photocoagulated rabbit retina. fpn f Ophthalmol $1983 ; 27: 138-48$

41 Martini B, Ryan S. Argon laser lesions of the retina; occurrence and origin of macrophages. Eur $\mathcal{F}$ Ophthalmol 1992;2. $51-7$

42 Richardson P, Boulton M, Duvall-Young J, et al. Immunocytochemical study of retinal diode laser photocoagulation in the rat. Br F Ophthalmol 1996;80:1092-8.

43 Richard A. The molecular and cellular biology of wound repair New York and London: Plenum Press, 1996. 